\title{
Study of life style determinants of overweight and obesity among school going adolescents in urban Jabalpur, Madhya Pradesh, India
}

\author{
Shashi Prabha Tomar*, Pradeep Kumar Kasar, Rajesh Tiwari
}

Department of Community Medicine, NSCBMC, Jabalpur, Madhya Pradesh, India

Received: 15 October 2016

Revised: 11 December 2016

Accepted: 20 December 2016

\section{*Correspondence:}

Dr. Shashi Prabha Tomar,

E-mail: tomarshashi9@gmail.com

Copyright: ( ) the author(s), publisher and licensee Medip Academy. This is an open-access article distributed under the terms of the Creative Commons Attribution Non-Commercial License, which permits unrestricted non-commercial use, distribution, and reproduction in any medium, provided the original work is properly cited.

\begin{abstract}
Background: Obesity has become a colossal epidemic causing serious public health concern and contributes to 2.6 million deaths worldwide every year. Indian data regarding current trends in childhood obesity are emerging. Considering the fact that India has rapidly growing middle class easily habituated for enormous lifestyle changes in recent decades responsible for developing potential platform for obesity among youths. Accordingly, the objective of the present study was to evaluate the associations between overweight, obesity and several lifestyle factors, including physical activity, sedentary behaviours among adolescents aged 10-17 years.

Methods: A cross-sectional study was carried out in two schools of Jabalpur located around medical college area , 184 students effectively interviewed by predesigned questionnaire regarding Socio-demographic profile ie current residence, age, mothers educational and occupational status and family size and life style practices like the physical activity questions designed to asses typical time spent per day on games and outdoor activity, on sedentary activities, including television (TV) viewing, video games, and computer and internet use. Data entry and data processing were carried out using the SPSS version 17 software and data analyses were applied using the appropriate statistical tests of significance.

Results: Prevalence of obesity and overweight: Of the 184 adolescents studied, $7.6 \%$ were obese and $2.2 \%$ were preobese.

Conclusions: Among all of the lifestyle factors assessed, overweight and obesity exhibited associations with less frequent physical activity, and more television and internet use.
\end{abstract}

Keywords: Adolescents, Life style, Obesity, Overweight

\section{INTRODUCTION}

Obesity has become a colossal epidemic causing serious public health concern and contributes to 2.6 million deaths worldwide every year. ${ }^{1}$ Indian data regarding current trends in childhood obesity are emerging. A recent study conducted among 24,000 school children in south India showed that the proportion of overweight children increased from 4.94 per cent of the total students in 2003 to 6.57 per cent in 2005 demonstrating the time trend of this rapidly growing epidemic. ${ }^{2}$ The proportion of school-age children affected will almost double by 2010 compared with the most recently available surveys from the late $1990 \mathrm{~s}$ up to $2003 .^{3}$ Current evidence indicates that obesity is a multi-factorial condition influenced by many variables, including genetic, demographic and lifestyle factors. ${ }^{4}$ Genetic and demographic variables such as family history of obesity, age, ethnicity and sex can not be modified. However, obesity-associated lifestyle factors are often modifiable. In fact, previous research has shown that childhood obesity is associated with many lifestyle factors, 
including sedentary behaviours, physical inactivity and unhealthy dietary choices. ${ }^{5-10}$

Information on lifestyle factors associated with obesity in adolescents in India are currently limited and the available data indicated that unhealthy lifestyle practices were generally correlated with BMI in Indian children and adolescents in fewer studies Considering the fact that in India has experienced enormous lifestyle changes in recent decades, rapidly growing middle class and rise of obesity among youths. ${ }^{11}$ Therefore, a better understanding of the relationships between obesity and lifestyle factors is necessary for effective prevention and management of obesity in youth. Also, local studies using a representative sample and validated instruments to assess lifestyle factors are particularly scarce. Accordingly, the objective of the present study was to evaluate the associations between overweight, obesity and several lifestyle factors, including physical activity, sedentary behaviours among adolescents aged 1017 years. Institutional ethical clearance was obtained prior to the study.

\section{METHODS}

\section{Research setting and study design}

A cross-sectional study was carried out in two, schools of Jabalpur located around medical college area. 100 students from each school were purposely selected for study .Out of these 16 students not cooperated,were not willing to pacipate so 184 students effectively interviewed .The total 184 students included in our study from the $5^{\text {th }}$ to $12^{\text {th }}$ grades were of age $10-17$ years.

\section{Data collection tools and techniques}

After a brief orientation, selected school children were subjected to the following experiments

\section{Anthropometric measurements}

The weight was measured using a commercial scale with an accuracy of $\pm 100 \mathrm{~g}$. The subjects asked to remove their footwear and wear minimal clothes before weighing them. The standing body height was measured to the nearest $0.5 \mathrm{~cm}$ by using a commercial stadiometer with the shoulder in a relaxed position and arms hanging freely and without shoes. The scales were recalibrated after each measurement. All measurements were carried out outside the class- room on individual after an interview with food frequency questionnaire.

Adolescents, overweight and obesity are defined using age and sex specific normograms for body mass index (BMI). Adolescents with BMI equal to or exceeding the age-gender-specific $95^{\text {th }}$ percentile are defined obese with $\geq 85$ percentiles were considered overweight, while those with $<85$ percentiles were considered desirable or lean. ${ }^{13}$
A predesigned questionnaire regarding Sociodemographic profile ie current residence, age, mothers educational and occupational status and family size, and life style practices like addiction habit, the physical activity questions designed to asses typical time spent per day on games and outdoor activity, on sedentary activities, including television (TV) viewing, video games, and computer and internet use were utilized as study instrument:

Assessment instrument was developed in a group discussion among students and faculty of department of community medicine further approved with pretesting the questionnaire in schools.

\section{Data management and data processing}

Data entry and data processing were carried out using the SPSS version 17 software (SPSS Inc.). Both the descriptive and inferential data analyses were applied using the appropriate statistical tests of significance (chisquare), A multivariate binary logistic regression model was generated by including study variables Confidence interval of $95 \%$ and significant difference of $\leq 0.05$ was found to be valid and convenient.

\section{RESULTS}

A total of 184 school children were included with their age ranging from 10 to 17 year (mean age, 15.64 \pm 1.42 years) and mean weight $49.39 \pm 12.27$ and mean height $161.53 \pm 10.60$

Prevalence of obesity and overweight: Of the 184 children studied, $18(9.7 \%)$ were obese and pre-obese. Among total14 (7.6\%) were obese and $4(2.2 \%)$ were pre-obese. With regard to gender-specific BMI $8.7 \%$, males whereas $12.3 \%$ females were obese and overweight. Over-weight and obese were higher in children of illiterate mothers, female students, among the older age group 14-17 years students. Obese and overweight were more who skip breakfast $(20 \%)$ it was found statistically significant with $\mathrm{p}$ value $<0.05$, surprisingly obesity and overweighs were found higher among Tiffin user $12.3 \%$ as compared to canteen.

Participation in cultural activities is also a significant predictor and surprisingly obese and overweighs were participate frequently in cultural events as compared to non-obese group. Obese and overweighs were more (19.9\%) among those who don't do exercise and don't play outdoor games as compare to those who regularly exercise and play outdoor games $(7.5 \%)$ and it was found statistically significant with $\mathrm{p}$ value $<0.05$.

Binary logistic regression was applied for life style factors and dietary habits, by using the dependent variables overweight and obesity revealed that change in eating habits(routine consumption of tea and coffee) during exams (OR: 2.75) were positively associated with 
obesity and overweight while having breakfast regularly $(\mathrm{OR}=0.32)$, and negative family history of obesity $(\mathrm{OR}=0.35)$ were negatively associated with obesity and overweight indicating its protective effect on obesity and overweight among adolescents students. Also, it was found in our study family history of diabetes was significantly associate with obesity and overweight (OR 5.152).
The odds of adolescents spending $>5$ hrs per day on playing video games/whatsapp/surfing net $(\mathrm{OR}=5.99)$, watching television while having meals $(\mathrm{OR}=1.64)$, change in routine consumption of tea or coffee $(\mathrm{OR}=2.27)$ of being obese or overweight were more as compared to the other counterparts, though these were not found to be statistically significant.

Table 1: Anthropometric sample characteristics in relation to the BMI classification.

\begin{tabular}{|lllllll|}
\hline \multirow{2}{*}{ Attribute } & BMI & Number & Mean & Std. deviation & Std. Error Mean & Significance \\
\cline { 2 - 7 } Height & Non obese & 166 & 161.2994 & 10.5163 & 0.8162 & 0.337 \\
\cline { 2 - 7 } & Pre obese and obese & 18 & 163.8333 & 11.3979 & 2.6865 & 0.377 \\
\hline \multirow{2}{*}{ Weight } & Non obese & 166 & 46.82 & 9.15 & 0.71 & $0.000^{* *}$ \\
\cline { 2 - 6 } & Pre obese and obese & 18 & 73.22 & 12.42 & 2.93 & $0.000^{* *}$ \\
\hline \multirow{2}{*}{ BMI } & Non obese & 166 & 17.8864 & 2.4824 & 0.1927 & $0.000^{* *}$ \\
\hline & Pre obese and obese & 18 & 27.1231 & 2.3045 & 0.5432 & $0.000^{* *}$ \\
\hline
\end{tabular}

Table 2: Association with obesity and overweight with socio-demographic, life style determinants ( $N=184)$.

\begin{tabular}{|c|c|c|c|c|}
\hline Variables & Normal & Obesity and overweight & Total & p value \\
\hline \multicolumn{4}{|l|}{ Age } & \multirow{3}{*}{0.949} \\
\hline $10-13$ & $38(90.5 \%)$ & $4(9.5 \%)$ & $42(22.83)$ & \\
\hline $14-17$ & $128(90.1 \%)$ & $14(9.9)$ & $172(77.17)$ & \\
\hline \multicolumn{4}{|l|}{ Sex } & \multirow{3}{*}{0.545} \\
\hline Male & $116(91.3 \%)$ & $11(8.7 \%)$ & $127(69.02)$ & \\
\hline Female & $50(87.7 \%)$ & $7(12.3 \%)$ & $57(30.98)$ & \\
\hline \multicolumn{4}{|l|}{ Mothers education } & \multirow{3}{*}{0.442} \\
\hline Illiterate & $66(89.2 \%)$ & $8(10.8 \%)$ & $74(40.22)$ & \\
\hline Literate & $100(90.9 \%)$ & $10(9.1 \%)$ & $110(59.78)$ & \\
\hline \multicolumn{4}{|l|}{ Socioeconomic status } & \multirow{3}{*}{0.784} \\
\hline Upper & $133(90.5 \%)$ & $14(9.5 \%)$ & $147(79.89)$ & \\
\hline Middle & $30(88.2 \%)$ & $4(11.8 \%)$ & $34(18.48)$ & \\
\hline Lower & $3(00.0 \%)$ & $0(0)$ & $3(1.63)$ & \\
\hline \multicolumn{4}{|c|}{ Participation in cultural activities } & \multirow{3}{*}{$0.04 *$} \\
\hline Yes & $94(86.2)$ & $15(13.8)$ & $109(59.54)$ & \\
\hline No & $72(96)$ & $3(4)$ & $75(40.76)$ & \\
\hline \multicolumn{4}{|l|}{ Outing for Dinner or lunch } & \multirow{5}{*}{$0.021 *$} \\
\hline Weekly & $16(72.7)$ & $6(27.3)$ & $22(11.96)$ & \\
\hline Monthly & $42(95.5)$ & $2(4.5)$ & $44(23.91)$ & \\
\hline More than a month duration & $57(93.4)$ & $4(6.6) 4$ & $61(33.15)$ & \\
\hline Never & $51(89.5)$ & $6(10.5)$ & $57(30.98)$ & \\
\hline \multicolumn{4}{|l|}{ Party with friends } & \multirow{3}{*}{0.4} \\
\hline Frequently & $78(86.7)$ & $12(13.3)$ & $90(48.91)$ & \\
\hline Occasionally & $20(90.2)$ & $5(7.5)$ & $25(13.59)$ & \\
\hline \multicolumn{4}{|l|}{ Out door Game and exercise } & \multirow{3}{*}{$0.036^{*}$} \\
\hline Regular (>5times/week) & $136(92.5)$ & $11(7.5)$ & $147(79.89)$ & \\
\hline Not regular $(<5$ times/week $)$ & $30(81.1)$ & $7(19.9)$ & $37(20.11)$ & \\
\hline \multicolumn{4}{|l|}{ Addiction (tobacco/smoking) } & \multirow{4}{*}{0.406} \\
\hline Yes & $10(83.3)$ & $2(16.7)$ & $12(6.522)$ & \\
\hline No & $156(90.7)$ & $16(9.3)$ & $172(93.48)$ & \\
\hline Total & $166(90.22)$ & $18(9.78)$ & & \\
\hline
\end{tabular}


Table 3: Logistic regression model for life style factors and their risk association with obesity and overweight.

\begin{tabular}{|c|c|c|c|}
\hline Life style factors & Adjusted odds ratio & $95 \% \mathrm{CI}$ & p-value \\
\hline \multicolumn{4}{|c|}{ Hours spend playing video games/whats app/ surfing net } \\
\hline $0-2$ hrs per day & 1.422 & $0.17-11.7$ & 0.744 \\
\hline $3-5$ & 0.824 & $0.05-14.4$ & 0.894 \\
\hline$>5$ & 5.998 & $1.5-8.6$ & 0.150 \\
\hline Never & - & - & - \\
\hline \multicolumn{4}{|c|}{ Watching T.V while taking meal } \\
\hline Yes & 1.641 & $0.52-5.25$ & 0.402 \\
\hline No & - & - & - \\
\hline \multicolumn{4}{|l|}{ Breakfast everyday } \\
\hline Regularly & 0.319 & $0.11-.89$ & 0.465 \\
\hline Not regularly & - & - & - \\
\hline \multicolumn{4}{|c|}{ Change in eating habits during exam } \\
\hline Yes & 1.5 & $1.67-4.9$ & $0.03 *$ \\
\hline No & - & - & \\
\hline \multicolumn{4}{|c|}{ Change in routine consumption of tea, coffee } \\
\hline Yes & 2.247 & $0.87-5.8$ & 0.09 \\
\hline No & - & - & - \\
\hline \multicolumn{4}{|c|}{ Change in sleep during exams } \\
\hline Yes & 1.029 & $0.37-2.8$ & 0.405 \\
\hline No & - & - & - \\
\hline \multicolumn{4}{|l|}{ History of obesity } \\
\hline No & 0.347 & $0.124-35$ & $0.04 *$ \\
\hline Yes & - & - & - \\
\hline \multicolumn{4}{|c|}{ Family history of diseases } \\
\hline Diabetes Mellitus & 5.152 & $1.619-16.39$ & $0.006^{*}$ \\
\hline Hypertension & 1.232 & $0.23-6.51$ & 0.806 \\
\hline Endocrinal dysfunction & 0.004 & $0-3.91$ & 0.822 \\
\hline Others & 0.944 & 0.1814 .93 & 0.946 \\
\hline Absent & - & - & - \\
\hline
\end{tabular}

*Significant with $\mathrm{p}$ value $<0.05$.

\section{DISCUSSION}

Lifestyle practices is an important determinants of health as Economic development of India has changed lifestyle habits. ${ }^{14}$ Modern life style practices coupled with physical inactivity have likely contributed to the increase in the prevalence of overweight and obesity in the children. ${ }^{15}$ Overall prevalence obesity and overweight adolescents in our study was found to be $9.7 \%$. Among total 184 adolescents surveyed $7.6 \%$ were obese and $2.2 \%$ were pre-obese which was consistent with study done in Delhi showed prevalence of obesity among affluent class students $7.4 \% .^{16}$ Similar studies are conducted India for prevalence of obesity and results are comparable to our study with respect to obesity prevalence. $^{17-20}$

With regard to gender-specific BMI, among males $8.7 \%$ whereas $12.3 \%$ among girls were obese and overweight showing higher prevalence among girls. One of the reasons being boys are more physically active than girls.
Deheeger $M$ et al mentioned Boys appear to engage in higher levels of physical activity, report more participation in sports, and have higher levels of aerobic fitness than females. ${ }^{21}$ Further gender differences in activity energy expenditure and reported physical activity become more apparent approaching puberty, because of the reported decline in physical activity in girls prior to puberty. ${ }^{22}$

In our study sedentary habits less exercise and less outdoor activities were more among obese and overweight, the difference were found statistically significant and odds of being obese or overweight among adolescents spending $>5$ hrs per day on playing video games/whatsapp/surfing net was 5.99. In a similar study by Laxmaiah et al logistic regression analysis revealed that the prevalence of overweight was 3 times higher in those not participating in outdoor games (OR: 2.75; CI: 1.56, 4.72), and 1.92 times higher in those watching television >or $=3 \mathrm{~h} / \mathrm{d}$ (OR: 1.92; CI: 1.16, $3.18) .^{23}$ 
Owen $\mathrm{N}$ et al mentioned in their study showed an inverse relationship between obesity and physical activity in children and a positive relationship between obesity and physical inactivity. ${ }^{24}$

In our study urbanization related behaviors like weekly outing for lunch was significantly higher among obese and preobese $27 \%$ as compared who never visited or visited monthly $(10.5 \%, 4.5 \%$ respectively). In similar studies on life style and obesity shown to promote obesity include frequent consumption of meals at fastfood outlets consumption of oversized portions at home and at restaurants. ${ }^{25-28}$

Study limitation. Due to limitation of resources done at small sample was taken. Results cannot as such generalized in general population despite best possible effort was put to select representative population.

\section{CONCLUSION}

The present study examined the associations of several lifestyle factors with overweight/ obesity in adolescents. Among all of the lifestyle factors assessed, overweight and obesity exhibited significant associations with less frequent vigorous physical activity, and skipping of breakfast, more use of television and internate. As adolescents is a important period for lifestyle adaptations, changes must include education, research and intervention, through the involvement of policy makers, health care providers, educators and parents for promoting a healthy diet and active lifestyles and it should be a national public health priority.

\section{ACKNOWLEDGEMENTS}

The authors thanks medical students of NSCBMC, for their participation in conducting in dietary survey and data collection and sincere thanks to principle and students of both school for their support and cooperation during survey.

Funding: No funding sources Conflict of interest: None declared

Ethical approval: The study was approved by the Institutional Ethics Committee

\section{REFERENCES}

1. WHO. Preventing Chronic Diseases: A Vital Investment. WHO. 2015. [Last cited on 2014 Mar 04]. Available from:http://www.who.int/ chp/chronic_disease_report/en/.

2. Raj M, Sundaram KR, Paul M, Deepa AS, Kumar RK. (2007) Obesity in Indian children: time trends and relationship with hypertension. Natl Med J India. 2007;20:288-93.

3. Raj M, Sundaram KR, Paul M, Deepa AS, Kumar RK. Obesity in Indian children: Time trends and relationship with hypertension. Natl Med J India. 2007;20:288-93.

4. Barlow SE. Expert Committee: Expert committee recommendations regarding the prevention, assessment, and treatment of child and adolescent overweight and obesity: summary report. Pediatrics. 2007;120:164-92.

5. Duncan S, Duncan EK, Fernandes RA, Buonani C, Bastos KD, Segatto AF, Codogno JS, Gomes IC, Freitas IF Jr. Modifiable risk factors for overweight and obesity in children and adolescents from Sao Paulo, Brazil. BMC Public Health. 2011;11(1):585.

6. Lazarou C, Soteriades ES. Children's physical activity, TV watching and obesity in Cyprus: the CYKIDS study. Eur J Public Health. 2010;20(1):707.

7. Croezen S, Visscher TL, Ter Bogt NC, Veling ML, Haveman-Nies A. Skipping breakfast, alcohol consumption and physical inactivity as risk factors for overweight and obesity in adolescents: results of the E-MOVO project. Eur J Clin Nutr. 2009;63:40512.

8. Dupuy M, Godeau E, Vignes C, Ahluwalia N. Socio-demographic and lifestyle factors associated with overweight in a representative sample of 11-15 year olds in France: results from the WHOCollaborative Health Behaviour in School-aged Children (HBSC) cross-sectional study. BMC Public Health. 2011;11:442.

9. Bradlee ML, Singer MR, Qureshi MM, Moore LL. Food group intake and central obesity among children and adolescents in the Third National Health and Nutrition Examination Survey. Public Health Nutr. 2010;13:797-805.

10. De Gouw L, Klepp KI, Vignerová J, Lien N, Steenhuis IH, Wind M. Associations between diet and (in)activity behaviours with overweight and obesity among 10-18-year-old Czech Republic adolescents. Public Health Nutr. 2010;13(10A):1701-7.

11. Rohilla R, Rajput M, Rohilla J, Malik M, Garg D, Verma M. Prevalence and Correlates of Overweight/Obesity Among Adolescents in an Urban City of North India. J Family Med Prim Care. 2014;3(4):404-8.

12. Donohoue PA. Obesity. In: Behrman RE, Kleigman RM, Jenson HB, editors. Nelson textbook of pediatrics. 17th ed. Philadelphia: WB Saunders; 2004. pp. 173-7.

13. Must, A, Dallal, GE Dietz, WH. Reference data for obesity: 85 th and 95 th percentile body mass index (wt/ht2) and triceps skinfold thickness. Am. J. Clin. Nutr. 1991;53:839-46.

14. Madhvapaty H, Dasgupta A. Study of Lifestyle Trends on Changing Food Habits of Indian Consumers. IOSR J Environmental Science, Toxicology and Food Technology. 2015;9:16-22.

15. Magbool G, Kaul KK, Corea JR, Osman M, AlArfaj A. Weight and height of Saudi children six to 
16 years from the eastern province. Ann Saudi Med. 1993; 13:344-9.

16. Kapil U, Singh P, Pathak P, Dwivedi R, Bhsin S. Prevelence of obesity among affluent adolescents school children in Delhi. Indian paediatr. 2002;39:449-52.

17. Kaneria Y, Singh P, Sharma DC. Prevalence of overweight and obesity in relation to socio economic conditions in two different groups of school age children of Udaipur city (Rajastan) J Indian Assoc Community Med. 2006;7:133-5.

18. Jelliffee DB. Assessment of nutritional status of the community. Geneva: World Health Organization; 1988.

19. Cole TJ, Bellizzi MC, Flegal KM, Dietz WH. Establishing a standard definition for child overweight and obesity: International survey. BMJ. 2000;320:1-6.

20. Sidhu S, Marwah G, Prabhjot Prevalence of overweight and obesity among the affluent school children of Amritsar, Punjab. Coll Antropol. 2005;29:53-5.

21. Deheeger M, Cachera-Rolland MF, Fontvieille AM. Physical activity and body composition in 10 year old french children: linkage with nutritional intake? Int J Obes. 1997;21:372-9.

22. Anderssen N, Wold B. Parental and peer in uences on leisure-time physical activity in young adolescents. Res Q Exerc Sport. 1992;63:341-

23. Laxmaiah A, Nagalla B, Vijayaraghavan K, Nair M. Factors affecting prevalence of overweight among
12- to 17-year-old urban adolescents in Hyderabad, India. Obesity (Silver Spring). 2007;15(6):1384-90.

24. Owen N, Bauman A, Booth M, Oldenburg B, Magnus S. Serial mass-media campaigns to promote physical activity: Reinforcing or redundant? Am J Public Health. 1995;85:244-8.

25. Lin BH, Guthrie J, Frazao E, editors. Nutrient contribution of food away from home: America's eating habits: Changes and consequences. Economic Research Service Report. Agriculture Information Bulletin No. 1999;750:213-39.

26. Pereira MA, Kartashov AI, Ebbeling CB, Van Horn L, Slattery ML, Jacobs DR Jr, et al. Fast-food habits, weight gain, and insulin resistance (the CARDIA study): 15-year prospective analysis. Lancet. 2005;365:36-42.

27. Al-Hazzaa HM, Musaiger AO, ATLS Research Group: Arab Teens Lifestyle Study (ATLS): Objectives, design, methodology and implications. Diabetes Metab Syndr Obes. 2011;4:417-26.

28. Cole T, Bellizzi M, Flegal K, Dietz W. Establishing a standard definition of child overweight and obesity worldwide: International survey. BMJ. 2000;320:1240-3.

Cite this article as: Tomar SP, Kasar PK, Tiwari R. Study of life style determinants of overweight and obesity among school going adolescents in urban Jabalpur, Madhya Pradesh, India. Int J Community Med Public Health 2017;4:554-9. 